\title{
Risk Management Behaviour and Company Policy for Insurance - a Part of Business Decision-Making*
}

\author{
by Arto Suominen **:
}

\section{Introduction}

Risk management is a process through which the risks threatening a company can be avoided, and losses caused by the damages minimised. The successful control of this process consists of several phases, from risk recognition to the implementation of different operations. Bieber divides the process of risk management into five areas of responsibility. ${ }^{\text {T The }}$ traditional view of risk management has been to label it as insurance purchasing. Its function was anchored tightly to damage-related risk. In the organisation, risk management was specialised as an area of Financial Management. Traditional risk management was of a strongly reactive nature: at the point when the existence of a new risk was recognised, the task of risk management was to find effective protection against that risk as inexpensively as possible. Risk management functioned under the conditions of insurance politics, and its effectiveness was measured in terms of savings in insurance premiums. ${ }^{2}$ Traditional risk management did not achieve managerial visibility, or bring special status. ${ }^{3}$

In a company with modern management, risk management functions as a part of that management, and its purpose is to improve the company's ability to reach its goal. ${ }^{4}$ Different classes of risks are integrated with each other, with the aid of risk management. It is considered necessary that the philosophy of risk management is adopted at each organisational level. The attitude toward different classes of risks, the level and forms of risk protection, and the policy employed by the company define the phenomenon in question, i.e. risk management behaviour.

* The author acknowledges editorial assistance by Professor Gerard COLSON (University of Liege). This paper was presented at the "Fourth Mini Euro Conference" devoted to Risk Management, held in Liege on May 1994. This conference, chaired by Professor Colson, was jointly organized by EURO (the European Federation of Operation Research Societies) and AEAI (l'Association Européenne des Assurés de l'Industrie).

** Turku School of Economics and Business Administration.

( A) Identification of Exposure, B) Evaluation of risk, C)Risk Control, D) Risk Financing and E) Risk Management Administration, Bieber 1987.

2 Shields, 1992.

3 Grose, 1987, 109.

4 Heilmann, 1990. 
Haimes examines modern risk management as a systemic, statistically based holistic process. ${ }^{5}$ In order to be effective, risk management must work as an integral part of the business management system. It is necessary for line management to adopt the process and operations of risk management at all organisational levels. In literature, the integrating and coordinating nature of the risk management function are emphasised. ${ }^{6}$ Systematic operation in the area of risk management denotes the tight tying in of risk questions to the company's strategic planning. Insurance and risk issues are no longer left in the shadow of issues perceived as more significant. The systematic nature and importance of the operation may be increased by drawing up company policy for risk management, e.g. in the form of a manual.

\section{The purpose of the research - theoretical perspectives}

The purpose of this study is to examine the risk management behaviour and insurance policies of Finnish companies. Companies' risk management decisions are analysed from the perspective of damage risks, and the following questions are taken up:

1) What kind of risks occur in the target companies and how should they be prevented against?

2) What kind of risk management behaviour do companies follow and why?

3) How does the company's policy towards insurance reflect its risk management behaviour?

4) Does risk management have links with decision-making?

The level of risk prevention varies considerably from company to company. The level of prevention selected by a company is examined by analysing the extent and cover of existing (valid) insurance contracts. Risk management solutions implemented by the management are interpreted using ther strategy types of Mintzberg and Waters, ${ }^{7}$ and Ting. ${ }^{8}$ According to Mintzberg and Waters, the strategy intended usually differs from the strategy realised. In Ting's view, a company may practice either integrated or defensive risk management. Integrated risk management emphasises preventive measures against damages. Risk management is weighted throughout the whole process, not simply with reference to the purchase of insurances. Defensive risk management is corrective in nature. The aim is to alleviate harmful effects.

In this study, the risk management solutions implemented are expressed in terms of the basic strategies of risk management behaviour, the dimensions of which are the level of risk management and management's strategic conciousness. A high level of risk management can be achieved through the application of insurance-weighted transfer strategy or a deliberate control strategy. The application of risk-aware strategy and shift strategy imply greater risk-taking and a lower level of risk management for companies. The significance of risk

\footnotetext{
5 Haimes, 1992.

6 Crockford, 1986.

7 Mintzberg and Waters, 1985, 257-272.

8 Ting, 1988.
} 
management operations is clearer in the deliberate and risk-aware strategies' fields. The weighing of the nature of risk, on the other hand, is left in the background in the insuranceweighted and shift strategy fields. Different risk management strategies are examined in Figure 1.

Figure 1: The basic strategies for risk management behaviour

\begin{tabular}{l|c|c|}
\multicolumn{1}{c|}{ High } \\
\cline { 2 - 3 } & $\begin{array}{c}\text { Strategy awareness } \\
\text { Deliberate } \\
\text { control strategy }\end{array}$ & $\begin{array}{c}\text { Low } \\
\text { Insurance-weighted } \\
\text { transfer strategy }\end{array}$ \\
$\begin{array}{l}\text { The level of risk } \\
\text { management } \\
\text { Low }\end{array}$ & Risk-aware strategy & Shift strategy \\
\cline { 2 - 3 } & Ren & \\
\hline
\end{tabular}

A low level of risk management heightens the significance of those risks which remain the company's own responsibility, in an aware or unaware fashion. It is characteristic to shift strategy, that management has neither the time nor the willingness to evaluate the company's state and its insurance solutions. By selecting a risk-aware strategy, the company consciously takes responsibility for a degree of risk exceeding its own solvency, and is not prepared to pay the costs caused by the risks.

\section{Risk management behaviour - six case studies}

To reach the objectives of the study, a thematic interview concerning risk management and insurance policies was conducted in 18 companies. The targets of the interviews were managers in charge of insurance and risk management. The interviews were built around the following main themes:

- information on insurance contracts and insurance premiums;

- the permanency of these contracts, and recently implemented changes;

- insurance company policy;

- bases for retaining certain risks, extent of retention;

- the organisation and decision-making of risk management;

- risk management operations, their extent and cover;

- an estimate of capital used in loss prevention;

- the strategic position of risk management and its links to decision-making;

- need for more effective risk management and its future profile.

The aim was to make the risk profiles of the target companies as versatile as possible. Companies' different risk management solutions widen both the theoretical and practical knowledge of the field. The application of the case method enables the production of theoretical evidence. Versatility was achieved by varying the company size, line of business, structure of ownership, company structure and the degree of internationalisation. This paper compares the risk management behaviour of six very different companies. Companies $A$ and $B$ represent large companies while $E$ and $F$ represent smaller ones. The line of business and company size are presented in Table 1. 
Table 1: The line business and turnover of the case companies

\begin{tabular}{llr} 
Company & Principal line of business & $\begin{array}{c}\text { Turnover 1992 } \\
1000 \text { US\$ }\end{array}$ \\
\hline A & wholesale trade & 4.732 .000 \\
B & wood processing and metal industries & 4.232 .000 \\
C & food and feed industries & 548.000 \\
D & dairy industry & 71.000 \\
E & plastics industry & 7.000 \\
F & precious metals industry & 2.000 \\
\hline
\end{tabular}

Case company A is a central wholesaler, and operates in real estate offering trade premises for around one thousand retailers. The company's risk philosophy does not weight the traditional risk of damage, but rather focuses on the crucial question of the company's vulnerability. The greatest risk is linked with the movement of material deliveries. The greatest catastrophe risks may be caused by the total destruction of one central store, or the total collapse of the EDP system. The aim of risk management is to secure an uninterrupted delivery system under all circumstances.

Case company B is highly internationalised, and its operation consists of separate industrial groups. Great quantities of physical assets are typical to the wood processing industry. The risks of the industrial units are expressed in EML values, which rise at their highest to US\$50-60 million. A risk characteristic of the chemical wood industry is that caused by consequential loss of production. There are no peculiar risks specific to the metal industry. Case B's risk categories will be examined globally as part of an international risk management programme.

Company C's lines of business fall within the food and feed industries and the chemical industry. The main products include edible fats, grain products, feed mixtures and paper chemicals. Case D processes around 90 million litres of milk per year. Special risks in the food industries arise from the perfect quality of raw products, and the securing of high-level hygiene at all stages of the production and delivery process. Typical risks are those of product liability. One possible risk in the feed industry is a dust explosion. For company D, transportation risks are also significant.

Company $\mathrm{E}$ manufactures polyurethane expanded plastic out of liquid raw materials. It is a part of a diversified Finnish group. A risk of fire is typical to this line of business, but due to improved raw materials and work methods it has decreased considerably. Company F used to be a family business but is, as the result of an acquisition, now owned by a Norwegian company in the same business area. A special risk is created in the precious metals industry by the high price of the raw material, gold. In companies $E$ and $F$ different chemicals and poisonous substances must be stored and handled, which makes environmental risks noteworthy for risk management. Companies $\mathrm{E}$ and $\mathrm{F}$ mainly operate in the domestic, Finnish market.

\section{Risk management operations}

Many different factors express risk management behaviour: companies' resources and policies, management visions, implemented risk management operations, and insurance company and possible captive solutions. Risk management decisions are made according to 
either decentralised, centralised, collective or situational philosophies. In the decentralised model, the management of each line or unit have to consider the state of risk management and the costs of risk prevention carefully. The decentralisation of decision-making has often meant changes in retention levels and the sums insured. At the corporate level, the aim is to calculate a sufficient insured sum and retention level, for a reasonable cost. This model was applied in companies A, B and C. In the smaller companies, the role of the managing director as a decision-maker proved quite central: the company follows a centralised model but is flexible according to the situation, as happened in company $E$. Where necessary, the financial manager steps into the role of decision-maker. In companies D and F, insurance decisions are made by the management team, i.e. the companies work to the collective model.

Differences between companies in their central risk management solutions are examined in Table 2. The premium share reflects the proportion of turnover $(\% / 00)$ that the company pays annually in insurance fees against loss prevention. Personal insurances, that is pensions, accident or unemployment insurances, are not included in the figures.

The risk profile focus describes the mutual shares of the insurance premiums paid by the companies. They were divided into five main groups as follows: 1) property insurances, 2) liability and product liability insurances, 3) consequential loss insurances, 4) transportation insurances, 5) vehicle insurances. The figures in bold for companies B and $\mathrm{E}$ denote that property insurances show a distinct domination in the companies' risk profiles, and that they spend more than half their insurance premiums in this area. In company $\mathrm{D}$, vehicle insurances dominate. The risk profile is quite uniform in companies $\mathrm{A}, \mathrm{C}$ and $\mathrm{F}$.

Table 2: Companies' risk management solutions: a comparative approach

\begin{tabular}{|c|c|c|c|c|c|}
\hline Company & $\begin{array}{l}\text { Risk profile } \\
\text { focus }\end{array}$ & Premium share & $\begin{array}{l}\text { Own } \\
\text { captive }\end{array}$ & $\begin{array}{l}\text { Cover of } \\
\text { operations }\end{array}$ & $\begin{array}{l}\text { Levels of } \\
\text { retention }\end{array}$ \\
\hline A & $5,4,1$ & 0,4 & No & High & Great retention \\
\hline B & $\mathbf{1}, 4,2$ & 4,2 & Yes & High & $\begin{array}{l}\text { Level varies by } \\
\text { unit }\end{array}$ \\
\hline $\mathrm{C}$ & $1,3,2$ & 1,4 & No & High & Small \\
\hline D & $\mathbf{5}, 1,2$ & 0,7 & Yes & Medium & Small \\
\hline$E$ & $\mathbf{1 , 3}$ & 2,4 & $\mathrm{X}$ & Medium & Medium \\
\hline $\mathrm{F}^{9}$ & $1,2,5,3$ & 4,0 & No & Medium & $\begin{array}{l}\text { Varies by area } \\
\text { of risk }\end{array}$ \\
\hline
\end{tabular}

Companies A, C, D, E and F apply the model of one main insurance company to their insurance solutions. Company B uses two captive companies. It obtains most of its insurance cover against domestic risks through a domestic insurance company. Company D's insurance company policy is very stable, since it obtains nearly all of its loss prevention insurances through a dairies mutual insurance company. Company $\mathbf{E}$ also uses a captive company owned by its parent company for protection against product liability risks.

The analysis of the insurance premiums demonstrated that different types of premium had a very different meaning for the case companies. The spectra of risks and the prevention solutions vary by company. The type of operation and the company's risk management

9 The premium for the property insurance does not include a fire risk, because the company operates in rented premises. The premium shares are not directly comparable. 
policy might indicate a multiple cost burden to one company. Companies $\mathrm{B}$ and $\mathrm{F}$ provide examples of this. In the wood processing industry, the costs of risks are much higher than in the wholesale trade. A small premium share does not imply negligence in covering a risk. As shown in Figure 1, the level of risk management may be considered high in each of the case companies. Risk management operations lie mainly in the deliberate control strategy and transfer strategy fields.

The company-specific characteristic of risk management behaviour was also reflected in retention policies. Current insurance business practice, the competitive situation, and management's intuitive estimate of the correct extent of retention affect retention decisions. The rules of thumb measuring risk-bearing capacity were well-known amongst risk management professionals, but their applications were not considered to be extensive. In each company, the percentage retention levels were counted smaller than the theoretical standard. ${ }^{10}$

As stated by Jablonowski, business managers do not make their decisions merely on the basis of a quantitative model.11 Retention followed the size of the company, but did not behave in a predictable fashion. Theoretical risk-bearing capacity and management decisions do not go hand-in-hand.

In company B's foreign units, retention policy occasionally differed from the Finnish unit, and the measured retention levels were lower than the Finnish. On the other hand, the global differences in the pricing of liability risks force optimal retention solutions to be found. Despite the fact that risk-bearing capacity and high retention levels did not show up as primary tools of risk management policy, the company may achieve the effect of a high level of retention by applying a certain kind of insurance programme. There was a tendency in the case companies to attempt to regulate the costs of risks by increasing the level of future retention. With competition in the insurance market, company B has succeeded in obtaining inexpensive insurance with a small retention.

\section{Strategic dimensions}

The evaluation of the position of risk management and its strategic presence proved a challenging task. Strategy was examined using a special measure expressing the position of risk management operations, their regularity and extent. Central areas in the strategy are represented by the regularity of risk analysis, the application of risk management policy, and covering loss prevention and protection solutions. Lauda and Sauerwein have used a similar interpretation of strategies. ${ }^{12}$

In the decision-making systems of cases A, B and C, risk management had a distinct strategic position. Companies $\mathrm{A}$ and $\mathrm{B}$ employed full-time risk management resources. In company $\mathrm{C}$, a full-time head of risk management was employed for two years. The versatile utilisation of resources strengthened the strategic position of risk management. Risk management chiefs were able to coordinate the whole field of risk management and implement plans accepted by management. In the weighing of risk questions, all classes of risks were covered. The application of the plan for catastrophe and written risk management policy further emphasised the strategic presence of risk management. It was stressed that risk

\footnotetext{
10 Hansman, 1982, Bawcutt, 1991.

11 Jablonowski, 1992.

12 Lauda and Sauerwein, 1993.
} 
management know-how must not be limited to the professionals, but that risk management questions must be a part of normal decision-making management. This linking is considered a sign of good management. ${ }^{13}$ In company A, strategy is supported by organisational solutions. The board member in charge of risk management is changed at regular intervals. Consequently, risk management know-how is not over-specialised as a separate function.

In the smaller case companies $\mathrm{D}, \mathrm{E}$, and $\mathrm{F}$, the strategic position was loosely interpreted. The regularity and coverage of risk management operations did not reach the level of the larger companies. There was no written risk management policy, and risk questions were rarely the targets of decision-making. No specific personnel resources were committed to the administration of risk management tasks. There was hardly any opportunity to forming strategic links to the decision-making system.

Companies' risk management behaviour was studied via a behaviour model (figure 1). The general starting point seemed to be that the level of risk management was chosen higher rather than lower. Care was emphasised more than high levels of retention. Behaviour was generally static with regard to both the risks insured and the insurance company chosen. There have been surprisingly few changes in the range of risks protected against recently. The decisions implemented in the case companies, such as the purchase of a fire extinguishing system or a considerable increase in percentage retention levels, implied strategic changes in risk management behaviour. Where a merger occurred, the company's risk management strategies were reweighted. Company acquisition or changes in proportions of ownership resulted in concrete pressure on companies $\mathrm{E}$ and $\mathrm{F}$ to change their traditional behaviour.

The most strongly emphasised operating areas of the behaviour model were deliberate control strategy and insurance-weighted strategy fields. Deliberate control strategy was most distinctly practised in companies A and B. In company C's risk management behaviour, ingredients of both deliberate control strategy and transfer strategy were present. A versatile, deliberate control strategy represents integrated risk management most clearly. ${ }^{14}$ In the application of the strategy, the following views and methods of operation are connected:

- insurance is considered as the last resort of risk management;

- emphasis on loss prevention;

- wide application of risk management operations, and the linking of insurance solutions to the company's risk management policy;

- versatile application of a captive programme;

- conscious utilisation of risk-bearing capacity, big and small retention in use.

An insurance-weighted transfer strategy represents a defensive model of operation. ${ }^{15}$ The requirements for the application of the strategy were seen best where the following features were linked to company risk management behaviour:

- conceiving of insurance as the primary tool for risk control;
13 Haimes, 1992, Kloman, 1992, Vojta, 1992.
14 Ting, 1988, 219-220.
15 Ting, 1988,187. 
- high insurance cover, low retention levels;

- low risks at own expense;

- high insurance premiums;

- no knowledge of the opportunities offered by risk-bearing capacity;

- narrow application of risk management operations.

In companies $\mathrm{D}, \mathrm{E}$, and $\mathrm{F}$, which applied insurance-weighted transfer strategy, the limits and opportunities of risk-bearing capacity were given less attention. In practice, the transfer of risks cannot work as the only tool for risk management. Despite the high level of protection, individual classes of risks were left as the company's own liability. The model based on transfer strategy represents reactive behaviour: as a risk is recognised, necessary coverage is sought with the aid of insurance. In company $F$, the change in ownership caused a change in risk management behaviour. The new owner transferred the risks of product liability and consequential loss, to shouldered by an insurance company.

Behaviour according to shift strategy might be exercised in temrs of an individual risk class, whereas total risk retention was an alien mode of operation in the case companies as a deliberate operating strategy. Philosophy based on shift strategy cannot be considered a relevant mode of operation in risk management. It cannot be seen as either integrated or defensive in nature. Rather, companies are drawn to the use of this strategy where there is insufficient knowledge of other modes of operation. The following behavioural expectations may lead to the use of this strategy:

- relying on the previous mode of operation;

- no knowledge of the existence of risks and their consequences;

- no knowledge of the options in risk management;

- negative attitude toward insurances and external services;

- seeing insurances as secondary issues;

- giving up insurances at random;

— the attitude "we've made do without insurances before".

The reliance on risk-aware strategy was also seen as problematic and dangerous. A conscious use of high retention levels was linked to the application of this strategy, which might be well-based in the case of certain classes of risks, due to high insurance premiums. In addition, a suitable insurance to protect against a risk is not always available. Environmental risks formed a concrete example of this. The following situational factors and behavioural features were seen to strengthen the options of applying a risk-aware, deliberate strategy:

- insurance is not the primary form of risk management behaviour;

- searching for the limits of risk-bearing capacity;

- no insurance available, risk entirely one's own liability;

- courageous use of great retention levels, consequences known;

- insurance against risk too expensive due to high premium;

- retaining some classes of risks such a transportation risk, product liability, consequential loss and loss of credit;

- the application of risk management operations. 
The size of the company and the input of risk management personnel is highly significant as regards the forming of a strategy. A deliberate control strategy is exercised as the basic strategy for risk management in companies whose resources create opportunities for the application of versatile risk management operations. Insuring is not preferred in companies A or B. The use of their own captive company for its part strengthened the application requirements for a deliberate control strategy. With the small case companies D, E and F, there was little room to manœuvre, and the company was relatively more tied to an insurance-based transfer strategy.

\section{REFERENCES}

BAWCUTT, P. A., "Captive Insurance Companies”, New York 1991.

BIEBER, R., "The Making of a Risk Manager - Part One", Risk Management, September 1987, pp.22-30.

CROCKFORD, N., "An Introduction to Risk Management”, Cambridge (U.K.), 1986.

GROSE, V., "Managing Risks. Sytematic Loss Prevention for Executives”, Englewood Cliffs, 1987.

HAIMES; Y., “Toward a Holistic Approach to Total Risk Management", The Geneva Papers on Risk and Insurance, July 1992, pp.314-321.

HANSMAN, R., "Determining Risk Retention Levels", Risk Management, July 1982, pp. 42-44.

HEILMANN; W.-R., "Risk Management and Insurance”, Forensic Engineering, 1990: 1-2, 119-134.

JABLONOWSKI, M., "Expert Systems for Risk Management”, Risk Management, September 1992, pp. 56-60.

KLOMAN, F., "Rethinking Risk Management”, The Geneva Papers on Risk and Insurance, July 1992, pp. 299-313.

LAUDA, K. and SAUERWEIN, E., "Betriebliches Risiko-Management in der Bundesrepublik Deutschland", Versicherungswirtschaft, Heft 18, 1993, pp. 1192-1196.

MINTZBERG, H. and WATERS, J., "Of Strategies, Deliberate and Emergent”, Strategic Management Journal, Vol. 6, 1985, pp. 257-272.

SHIELDS; E., "Measuring the Risk Manager's Performance", Risk Management, March 1992, pp. $46-50$.

TING, W., "Multinational Risk Assessment and Management”, New York, 1988.

VOJTA, G., "Build a Framework for Risk Management", Financial Executive, November-December 1992, pp. 34-37. 